\title{
Detection of Colon Polyps in India-A Large Retrospective Cohort Study (DoCPIr)
}

\author{
Nitin Jagtap ${ }^{1, \odot}$ Aniruddha Pratap Singh ${ }^{1}$ Pradev Inavolu ${ }^{1}$ Manu Tandan ${ }^{1}$ Shubhankar Godbole \\ Pranav Ambardekar ${ }^{1}$ Anuradha Sekaran² Sundeep Lakhtakia1,๑ Mohan Ramchandani ${ }^{1}$ \\ Rakesh Kalapala ${ }^{1}$ Rajesh Gupta ${ }^{1}$ P Manohar Reddy ${ }^{1}$ Zaheer Nabi ${ }^{1}$ Radhika Chavan ${ }^{1, \odot ~ G ~ V e n k a t ~ R a o ~}{ }^{3}$ \\ D Nageshwar Reddy ${ }^{1}$
}

${ }^{1}$ Department of Medical Gastroenterology, Asian Institute of Gastroenterology, Hyderabad, Telangana, India

2Department of Pathology, Asian Institute of Gastroenterology, Hyderabad, Telangana, India

${ }^{3}$ Department of Surgical Gastroenterology, Asian Institute of Gastroenterology, Hyderabad, Telangana, India

Address for correspondence Nitin Jagtap, MD, DNB, Asian Institute
of Gastroenterology, Somajiguda, Hyderabad, Telangana 500082, India (e-mail: docnits13@gmail.com).

J Digest Endosc 2021;12:63-66.

\section{Abstract \\ Keywords \\ - Colonoscopy \\ - Adenoma \\ - Adenoma with Advanced Pathology \\ - Colorectal Cancer \\ - Screening \\ - India}

Objective Colorectal cancer (CRC) is an emerging public health problem in Asia and India. However, there is scarcity of data on CRC and adenoma. We aimed to study prevalence and characteristics of colonic polyps in a large retrospective cohort.

Methods For this retrospective single center study, all patients with age $>18$ years undergoing colonoscopy from January 2018 to December 2019 were included. Age, gender, and polyp characteristics were collected from endoscopy and histology database. Patients with incomplete histology reports and anal canal polyps were excluded. Based on histology, polyps were divided into adenocarcinoma, adenoma with advanced pathology (AAP; size > $10 \mathrm{~mm}$, villous morphology or high-grade dysplasia), nonadvanced adenomas (nAAP), and nonadenomas.

Results Overall colon polyp prevalence was $10.18 \%$ (3551/34893). The mean age (standard deviation [SD]) was 51.51 (14.84) with $75.4 \%$ males, of which 128 (3.6\%) were adenocarcinoma. A total of 1514 (42.64\%) were adenomas; 344 (9.7\%) were AAP and 1170 (32.9\%) were nAAP. The remaining 1909 (53.8\%) were nonadenomas. Colonic adenoma prevalence after excluding adenocarcinoma was 4.35\% (1514/34893). Adenocarcinoma (68.8\% vs. $31.2 \%)$, AAP (70.6\% vs. $29.4 \%$ ), other adenomas $(75.4 \%$ vs. $24.6 \%$ ), and nonadenomas ( $76.7 \%$ vs. $23.3 \%$ ) were significantly higher in male compared with female $(p<0.05)$. Adenomas and adenocarcinomas were more common in left colon and rectum than right colon $(p<0.05)$. The mean age (SD) were significantly lower in nonadenomas than adenocarcinomas, AAP, and other adenomas ( $p$ 0.0001; 49.25 [14.84] vs. 55.97 [12.47], 54.78 [16.40], 53.76 [13.71]).

Conclusions The prevalence of colonic adenoma in India is $4.35 \%$. Male gender and increased age were associated with increased risk of colonic adenoma and adenocarcinoma, which is more common in left colon and rectum. Prospective multicenter studies are required for evaluation of other risk factors of CRC and colonic adenomas. published online January 11, 2021
DOI https://doi.org/ $10.1055 / \mathrm{s}-0041-1731977$ ISSN 0976-5042
(C) 2021. Society of Gastrointestinal Endoscopy of India.

This is an open access article published by Thieme under the terms of the Creative Commons Attribution-NonDerivative-NonCommercial-License, permitting copying and reproduction so long as the original work is given appropriate credit. Contents may not be used for commercial purposes, or adapted, remixed, transformed or built upon. (https://creativecommons.org/licenses/by-nc-nd/4.0/). Thieme Medical and Scientific Publishers Pvt. Ltd. A-12, 2nd Floor, Sector 2, Noida-201301 UP, India 


\section{Introduction}

Colorectal carcinoma (CRC) is a common public health problem worldwide. The overall prevalence of CRC in Asian countries and India is reported to be low compared with Western countries. ${ }^{1}$ With industrialization and changing socioeconomics in Asia, the burden of CRC in increasing., ${ }^{2,3}$ The age-standardized incidence of CRC in India increased from 4.3 in 2008 to 7.2 per 100,000 male population in 2012 . It is expected to rise by $60 \%$ in males and $37 \%$ in females by $2026.4,5$

Colonic adenomas are recognized as precursor of majority of CRCs through adenoma carcinoma sequence. ${ }^{6}$ The prevalence of colonic adenoma in the Western population of age more than 50 years is $20 \%$ to $53 \%{ }^{7}$ This prevalence is concordant with CRC prevalence in the population. The US National Polyp Study demonstrated that colonoscopy and polypectomy could prevent $76 \%$ to $90 \%$ of colorectal adenomas. ${ }^{8}$

There is limited data on prevalence of colorectal adenoma from Indian subcontinent. The prevalence of colonic adenoma in India is between $5.4 \%$ and $6.7 \%{ }^{9,10}$ However, both the studies were single-center and of small sample size. In the current study, we aimed to evaluate the prevalence of colorectal adenoma and histopathological characteristics of colonic polyps in a retrospective cohort.

\section{Methods}

The institutional review board has approved the study. All consecutive adult patients (age $>18$ years) who underwent colonoscopy between January 2018 and December 2020 at a tertiary care center were screened for analysis. Patients with at least one colonic polyp were included in the study. The baseline demographic characteristics included age and sex along with colonoscopic and histological characteristics of polyp, which were collected from endoscopic and histopathological database.

Colonoscopies were performed after standard preparation of $2 \mathrm{~L}$ of polyethylene glycol by senior gastroenterologist and trainee gastroenterologist under supervision of former. Quality of colonoscopy preparation was assessed by the Boston bowel preparation scale. ${ }^{11}$ Patients with poor or inadequate preparation were advised for repeat colonoscopy on subsequent day after repeat preparation. There was no fixed protocol about colon withdrawal time during study period; it was as per discretion and satisfaction of endoscopist.

Patients with anal canal or ileal polyps and colonic polyps, where histological characteristics were incomplete or unavailable, were excluded from analysis. Patients who underwent screening colonoscopy or incomplete colonoscopy without obstructive lesion were also excluded. We excluded patients who underwent screening colonoscopy , those who previously underwent colonoscopic polypectomy or colorectal surgery for CRC, and those with family history of CRC, as these patients are considered as high risk for colorectal adenomas. After histopathological characteristics, colonic polyps were classified into adenocarcinoma, adenomatous polyps or nonadenomatous polyps. The standard definitions were used to characterize histologically different types of polyps. ${ }^{12,13}$ Adenomatous polyps were considered as adenoma with advanced pathology (AAP), if size was more than $10 \mathrm{~mm}$, villous morphology or high-grade dysplasia. If these features were absent, these were considered as nonadvanced adenomas (nAAP). Patients with multiple polyps were grouped in adenocarcinoma, AAP, or nAAP, if at least one polyp had features of one the mentioned subgroup.

\section{Results}

A total of 36426 colonoscopy were performed between January 2018 to December 2019, of which 1533 were excluded for following reasons: incomplete colonoscopic examination without obstructive lesions, screening colonoscopy and incomplete histopathological reports. The common indications for colonoscopy were unexplained abdominal pain $(2646 ; 74.5 \%)$, anemia (206; 5.8\%) per rectal bleeding (873; 24.6\%), weight loss (163; 4.6\%), and evaluation for liver or lung metastasis (36; $1 \%)$.

Overall colon polyp prevalence was 10.18\% (3551/34893; $18.08 \%$ more than one polyp). The mean age (SD) was 51.51 (14.84) with $75.4 \%$ males, of which 128 (3.6\%) were adenocarcinoma. A total of 1514 (42.64\%) were adenomas; 344 (9.7\% of total polyps) were AAP, and 1170 (32.9\% of total polyps) were nAAP. The remaining 1909 (53.8\%) were nonadenomas. Colonic adenoma prevalence after excluding adenocarcinoma was $4.35 \%$ (1514/34893). Adenocarcinoma (68.8\% vs. $31.2 \%$ ), AAP (70.6\% vs. $29.4 \%$ ), nAAP (75.4\% vs. $24.6 \%$ ), and nonadenomas (76.7\% vs. $23.3 \%$ ) were significantly higher in males compared with females ( $p$ 0.05). - Table 1 depicts summary of the study population. The mean age (SD) were significantly lower in nonadenomas than adenocarcinomas, AAP, and nAAP ( $p$ 0.0001; 48.25 [15.75] vs. 55.97 [12.47], 54.29 [17.59], 53.66 [15.75]). The location of adenocarcinoma was rectum in 37 (28.91\%), left colon which included sigmoid and descending colon 48 (37.5\%), and right colon which included cecum, ascending and transverse colon 43 (33.59\%) patients. There was no significant difference in age of patients with adenocarcinoma location in rectum or left colon (54.60 \pm $12.75)$ and right colon (58.67 $\pm 11.57 ; p$ 0.081).

There were total 1514 (42.64\%) adenomas, of them 344 (9.7\%) were AAP and 1170 (32.9\%) were nAAP. Tubular adenoma was the most common histological type with 1241 (81.97\%), followed by tubulovillous 177 (11.69\%), and villous 96 (6.3\%). Of 1241 tubular adenomas, 71(5.7\%) were either showing high-grade dysplasia or size more than $10 \mathrm{~mm}$. In tubulovillous and villous adenoma, high-grade dysplasia or size more than 10 was seen in $52.38 \%$ (143/273) patients. The mean (SD) age of patients with adenoma was 53.80 (14.88) years. The interquartile range was 45 to 64 years. - Table 2 depicts age-wise distribution on colonic polyps. The proportion of nonadenoma polyps were higher than adenomatous polyps in patients of age less than 50 years; between 51 to 60 years, proportion of adenoma and nonadenoma appears comparable, and after 60 years, proportion of adenomatous polyps is more than nonadenomas. In nonadenomatous polyps (1909), hyperplastic ( $n=925 ; 48.45 \%)$ 
Table 1 Summary of the study population $(n=3551)$

\begin{tabular}{|l|l|l|l|l|}
\hline Parameter & $\begin{array}{l}\text { Adenocarcinoma } \\
(n=128)\end{array}$ & $\begin{array}{l}\text { AAP } \\
(n=344)\end{array}$ & $\begin{array}{l}\text { nAAP } \\
(n=1,170)\end{array}$ & $\begin{array}{l}\text { Nonadenoma } \\
(n=1,909)\end{array}$ \\
\hline Age, mean (IQR) years & $55.97(47-65)$ & $54.29(45.25-66)$ & $53.66(45-63)$ & $48.92(39-61)$ \\
\hline Sex & & & & $1465(76.7)$ \\
\hline Male, $n(\%)$ & $88(68.8)$ & $243(70.6)$ & $882(75.4)$ & $444(23.3)$ \\
\hline Female, $n(\%)$ & $40(31.2)$ & $101(29.4)$ & $288(24.6)$ & \\
\hline Location & & & & $275(23.5)$ \\
\hline Rectum, $n(\%)$ & $37(28.9)$ & $122(35.5)$ & $484(41.4)$ & $708(37.1)$ \\
\hline Left colon, $n(\%)$ & $48(37.5)$ & $166(48.3)$ & $411(35.1)$ & $485(25.4)$ \\
\hline Right colon, $n(\%)$ & $43(33.6)$ & $56(16.3)$ & \\
\hline
\end{tabular}

Abbreviations: AAP, adenoma with advanced pathology; IQR, interquartile range; nAAP, adenoma without advanced pathology.

Table 2 Age-wise colonic polyp distribution

\begin{tabular}{|l|l|l|l|l|l|}
\hline Age group & Adenocarcinoma $(\boldsymbol{n}=128)$ & $\begin{array}{l}\text { AAP } \\
(\boldsymbol{n}=344)\end{array}$ & $\begin{array}{l}\text { nAAP } \\
(\boldsymbol{n}=1,170)\end{array}$ & $\begin{array}{l}\text { Non adenoma } \\
(\boldsymbol{n}=1,909)\end{array}$ & $\begin{array}{l}\text { Total } \\
(\boldsymbol{n}=3,551)\end{array}$ \\
\hline$<40$ years & $12(9.4 \%)$ & $64(18.6 \%)$ & $204(17.5 \%)$ & $538(28.2 \%)$ & $818(23.1 \%)$ \\
\hline 41 to 50 years & $30(23.4 \%)$ & $58(16.9 \%)$ & $232(19.8 \%)$ & $409(21.4 \%)$ & $729(20.5 \%)$ \\
\hline 51 to 60 Years & $34(26.6 \%)$ & $77(22.4 \%)$ & $335(28.6 \%)$ & $474(24.8 \%)$ & 920 \\
& & & & & \\
\hline$>60$ years & $52(40.6 \%)$ & $145(42.1 \%)$ & $399(34.1 \%)$ & $488(25.6 \%)$ & $1084(30.5 \%)$ \\
\hline
\end{tabular}

Abbreviations: AAP, adenoma with advanced pathology; nAAP, adenoma without advanced pathology.

and inflammatory ( $n=820 ; 42.96 \%$ ) polyps were the most common. The remaining 164 (8.59\%) were hamartomatous, benign epithelial, lipomatous, lymphoid, and carcinoids. Nonadenomatous polyps were more in rectum or left colon compared with right colon (74.59\% vs. $24.41 \%, p 0.0001$ ).

\section{Discussion}

Colonic polyps is one of the common findings during colonoscopy. There is scarcity of data from India about colonic polyps detected during colonoscopy. In the current study, colon polyp prevalence is $10.18 \%$, of which $42.64 \%$ were adenomas. Overall adenoma prevalence was $4.35 \%$, with mean age (interquartile range [IQR]) of 53.80 (45-64) years. No-adenoma polyps were the most common type of polyps in the present study. Mean age was significantly lower in nonadenoma polyps compared with adenocarcinomas and adenomas. All types of polyps were more common in males and in rectum or left colon.

Majority of CRC arose from adenomatous polyps. ${ }^{2}$ Adenoma detection by colonoscopy and removal by polypectomy can prevent CRC., ${ }^{1,6}$ The prevalence of adenoma varies with patients' age, sex and family history but is concordant with background rate of CRC in the population. ${ }^{14}$ Age is the most important independent determinant of adenoma prevalence. ${ }^{15,16}$ The adenoma prevalence in current study was $4.35 \%$ with mean age (IQR) of 53.80 (45-64) years. Previous studies from India reported $6.73 \%$ adenomas (12.7\% overall polyps)..$^{10}$ In a large series from western India, adenoma prevalence was $5.43 \%$ (10.3\% overall polyps) with mean age of 59.5 (14.8) years. ${ }^{9}$ The IQR for adenoma in the current series is 45 to 64 years.

In a series of 515 colorectal polyps from western India, 270 (52.4\%) were adenoma, 15 (2.9\%) were adenocarcinoma, and hyperplastic and inflammatory polyps were $15 \%$ each. ${ }^{9}$ In our series of 3551 patients, 1514 (42.64\%) were adenomas, 1909 (53.8\%) were nonadenomas, and 128 (3.6\%) adenocarcinoma. Similar to previous studies, we also found tubular adenoma and male preponderance among adenomatous polyps. ${ }^{9,10}$ As compared with Western data, the overall prevalence to colonic adenoma appears lower in Indian population; however, within colonic adenoma, proportions of tubular, tubulovillous and villous adenomas appear comparable.,17

The prevalence, incidence, and case fatality of CRC varies in Asian countries. ${ }^{1}$ Japan, Korea, China, and Thailand are more affected by CRC compared with India, Indonesia and Vietnam. ${ }^{18}$ The five-year prevalence of CRC in Japan, Malaysia, Singapore, China and Korea is higher than in other Asian countries ( $>46.5 / 100,000)^{18}$ as compared with $8.3 / 100,000$ in India. ${ }^{1,18}$ Recent estimates suggest increasing trend of CRC in India by 2026. Age-standardized incidence of CRC in India in expected to increase by $60 \%$ in males and $37 \%$ in females. ${ }^{4,5}$ Considering India's vast population, and with increasing Westernization of lifestyle, CRC may emerge as public health problem. Colonoscopy and polypectomy can be simple and effective tool to prevent CRC, a well-established practice in the West. ${ }^{6-8}$

Apart from being a single-center and retrospective study, the current study has certain other limitations. We have not evaluated other risk factors such as family history, diet and 
lifestyle, including smoking, in the current study. There was no fixed protocol about colon withdrawal time during study period; it was as per discretion and satisfaction of endoscopist. We also do not have data on cecal intubation rate, as incomplete colonoscopies were not included in the analysis.

This large sample study highlights the need to develop a screening colonoscopy program. Male gender and increased age were associated with increased risk of colonic adenoma and adenocarcinoma, which is more common in left colon and rectum. As prevalence of CRC is increasing, a prospective, multicenter study is required to define average and high risk population in the Indian population.

\section{Author Contributions}

Concept and design: Nitin Jagtap, Aniruddha Pratap Singh; Pradev Inavolu; Materials: Nitin Jagtap, Aniruddha Pratap Singh; Data collection and/or processing: Nitin Jagtap, Pradev Inavolu, Shubhankar Godbole, Pranav Ambardekar; Analysis and/or interpretation: Jagtap Nitin, Aniruddha Pratap Singh, Pradev Inavolu; Literature search: Aniruddha Pratap Singh, Nitin Jagtap; Writing manuscript: Nitin Jagtap, Manu Tandan, P Manohar Reddy; Critical review: Mohan Ramchandani, Rajesh Gupta, Sundeep Lakhtakia, Rakesh Kalapala, Anuradha Sekaran, Zaheer Nabi, Radhika Nabi, GV Rao, Reddy DN; Final approval: all authors.

\section{Financial Disclosure}

There is no financial disclosure.

\section{Conflict of Interest}

All authors declare no conflict of interest.

\section{Reference}

1 Wong MC, Ding H, Wang J, Chan PS, Huang J. Prevalence and risk factors of colorectal cancer in Asia. Intest Res 2019;17(3):317-329

2 Sung JJ, Ng SC, Chan FK, et al. Asia Pacific Working Group. An updated Asia Pacific Consensus Recommendations on colorectal cancer screening. Gut 2015;64(1):121-132

3 Patil PS, Saklani A, Gambhire P, et al. Colorectal cancer in India: an audit from a tertiary center in a low prevalence area. Indian J Surg Oncol 2017;8(4):484-490
4 Cherian T, Mahadevan P, Chandramathi S, Govindan J, Mathew IL. Increasing cancer incidence in a tertiary care hospital in a developing country, India. Indian J Cancer 2015;52(1):133-138

5 D'Souza ND, Murthy NS, Aras RY. Projection of cancer incident cases for India -till 2026. Asian Pac J Cancer Prev 2013;14(7):4379-4386

6 Hull MA, Rees CJ, Sharp L, Koo S. A risk-stratified approach to colorectal cancer prevention and diagnosis. Nat Rev Gastroenterol Hepatol 2020;17(12):773-780

7 Lieberman DA, Williams JL, Holub JL, et al. Race, ethnicity, and sex affect risk for polyps $>9 \mathrm{~mm}$ in average-risk individuals. Gastroenterology 2014;147(2):351-358, quiz e14-e15

8 Winawer SJ, Zauber AG, Ho MN, et al. The National Polyp Study Workgroup. Prevention of colorectal cancer by colonoscopic polypectomy. N Engl J Med 1993;329(27):1977-1981

9 Amarapurkar AD, Nichat P, Narawane N, Amarapurkar D. Frequency of colonic adenomatous polyps in a tertiary hospital in Mumbai. Indian J Gastroenterol 2016;35(4):299-304

10 Jain M, Vij M, Srinivas M, et al. Spectrum of colonic polyps in a south Indian urban cohort. Journal of Digestive Endoscopy 2019;08:119-122

11 Calderwood AH, Jacobson BC. Comprehensive validation of the Boston bowel preparation scale. Gastrointest Endosc 2010;72(4):686-692

12 Jass JR. Classification of colorectal cancer based on correlation of clinical, morphological and molecular features. Histopathology 2007;50(1):113-130

13 Robert ME. The malignant colon polyp: diagnosis and therapeutic recommendations. Clin Gastroenterol Hepatol 2007;5(6):662-667

14 Correa P. Epidemiology of polyps and cancer. Major Probl Pathol 1978;10:126-152

15 Imperiale TF, Wagner DR, Lin CY, Larkin GN, Rogge JD, Ransohoff DF. Results of screening colonoscopy among persons 40 to 49 years of age. N Engl J Med 2002;346(23):1781-1785

16 Strul H, Kariv R, Leshno M, et al. The prevalence rate and anatomic location of colorectal adenoma and cancer detected by colonoscopy in average-risk individuals aged $40-80$ years. Am J Gastroenterol 2006;101(2):255-262

17 Corley DA, Levin TR, Doubeni CA. Adenoma detection rate and risk of colorectal cancer and death. $\mathrm{N}$ Engl J Med 2014;370(26):2541

18 Bray F, Ferlay J, Soerjomataram I, Siegel RL, Torre LA, Jemal A. Global cancer statistics 2018: GLOBOCAN estimates of incidence and mortality worldwide for 36 cancers in 185 countries. CA Cancer J Clin 2018;68(6):394-424 